\title{
An Experimental Study on Social Media Advertising for Charity*
}

\begin{abstract}
Athanasios Tsadiras ${ }^{1}$, Marina Nerantzidou ${ }^{2}$
Abstract:

Purpose: Nowadays, more and more charity organizations attempt to use advertainment through social media to increase their appeal, attract supporters and gather more online donations. The purpose of this paper is to investigate the effectiveness of such advertisements through the Facebook social media tool to specific target groups in order to assist charities to choose the most profitable target groups to aim to and design accordingly their digital strategy.
\end{abstract}

Design/Methodology/Approach: Within the framework of this objective, an experimental investigation was performed. A well-known Greek charity was selected to be examined and in cooperation with this charity, several experimental Facebook advertisements/campaigns were chosen to be performed. Each experiment/campaign was aiming to a different target group in order to identify both the behaviour of each group and also the most profitable groups.

Findings: Based on the outcome of each campaign, various results were found regarding the profile of the supporters of the charity that responded to the campaigns. These results are presented in the paper and they identify the response rate of the Facebook users to the advertisement based a) on various of their characteristics such as their age, sex, use of device, whether they are "Facebook friends" with the charity or not, etc. and also b) the characteristics of the advertisement (e.g. image or video). In the study, the Return On Advertising Spend (ROAS) was used as marketing metric.

Practical Implications: Conclusions are drawn and presented, regarding the best target groups that a charity can aim to. Future work is also proposed in the paper, to assist the further investigation on how charities can use Internet to their advantage and establish a successful and effective digital strategy.

Originality/Value: The main contribution of this study is to outline the profile of donors and the variables that contribute to a successful online charity advertising campaign through a social media tool.

Keywords: Digital strategy, campaigns, donations, user profile, Facebook, return on advertising spend (ROAS).

JEL codes: M3, M37.

Paper type: Research article.

\footnotetext{
${ }^{1}$ Corresponding author, Associate Professor, Aristotle University of Thessaloniki, School of Economics, tsadiras@econ.auth.gr

${ }^{2}$ MSc in Informatics and Business Administration, Aristotle University of Thessaloniki, marina.nerantzidou@gmail.com
}

*An earlier version of this article has been presented in ICABE 2019 www.icabe.gr 


\section{Introduction}

The current era is characterized by absence of geographical boundaries. Internet access and social media bring closer a vast number of people. This has also an impact on fundraising, giving it new dimensions and making it a subject of multifaceted study. The primary feature is that organizations are now able to pool extremely large resources for a purpose, following modern strategies that utilize these tools.

Following the trend of the time, donations made worldwide via the internet are rapidly increasing. The success of fundraising is no longer solely related to the organisation's financial capability, but to its ability to effectively penetrate the web and exploit it appropriately. It is important for charities to outline the profile of people who make donations. This process is multidimensional and contains many variables. Some of these are the level of education, the economic background, the political and religious beliefs as well as involvement with volunteering (Schervish and Havens, 1997; Wang and Graddy, 2008). It should be noted that the people who eventually donate, are the ones who have been asked to do so. Otherwise, they will not do it voluntarily (Steele and Elder, 1992). Thus, when an organization successfully establish a strong relationship with a prospective donor, it is very likely to receive the donation after a simple request.

This research attempts to outline the profile of donors and the variables that contribute to a successful online charity advertising campaign. Successful web promotion is defined as the one that increases the appeal of the organization and raises money through donations. In order to investigate the online promotion strategy of a charity, the implementation of such an internet plan is presented. It is taking place in a Greek charity located in Thessaloniki, which is active in the field of health and has presence in various cities in Greece.

\section{Literature Review}

Donation is defined as a gift or contribution for charity, for the benefit of other people, groups or organizations. It has various forms, such as cash, time, goods, resources, and body parts (Bendapudi et al., 1996). Fundraising is based on volunteering and can be found on various scales. From fundraising to a single person sidewalk stand, to international-wide campaigns involving multiple people and using all available media, internet and social media. However, attracting and retaining donors can be very time consuming and not an easy task no matter the fundraising scale (Ncvo, 2018).

A key factor for donors is good mood. It effects both general and online donation. The personality traits of the individual also contribute to their motivation. Donors who are familiar with technology and Internet are more likely to donate online (Chen and Givens, 2013). At the same time information about the campaign procedure and the donors profile increases the charity's credibility and transparency (Shier and Handy, 2012). 


\subsection{Charities and Social Media}

Technology has changed the perspective of many things, even the way help is offered (Angelou, 2018). Charities and foundations are slowly turning to digital help, to keep up with the growing audience and potential donors. Social media are incredibly powerful as they have a "human voice" and can promote collaboration (Smith, 2012). They are useful because they allow brands, businesses, services, and organizations to connect and communicate with people in a much simpler and exciting way than traditional advertising methods.

A major advantage of social media is that they provide measuring tools, that can easily quantify the success of any organization's actions. This can make campaigns more targeted and way more effective. Moreover, one of the most important features of online communication, is that the cost is much lower than traditional methods (Strawmyer, 2014). Research shows that the limited cost of using social media has given the opportunity to small organizations to engage in philanthropic campaigns, that otherwise would not be able to do so (Ogden and Laura, 2009).

\subsection{Online Advertising}

Internet advertising is defined as "any paid form of promoting ideas, goods or services, whether for-profit or non-profit organizations, conducted online" (Zotos, 2008). The main features of online advertising are user interaction, interpersonal communication, and sending personalized advertising messages. Some of the major technology companies, including Google and Facebook, rely mainly on online advertising to raise money (Goldfarb, 2014). Google and Facebook make up one-fifth of global ad revenue, generating $\$ 106.3$ billion, almost double the revenue from 2012 (Kollowe, 2017). Internet advertising has become the largest advertising medium in the world, far surpassing traditional television advertising.

There are many types of internet advertising methods such as banners, email advertising, blogs advertising, mobile advertising, video advertising, popup windows, websites, social networking advertising, etc. Social media is the "group of web-based applications, ideological and technological foundations of Web 2.0 that allow the creation and exchange of user-generated content" (Kaplan and Haenlein, 2010). Consumers consider that social media provide a more reliable source of information about products and services than traditional corporate communications (Foux, 2006). Due to the global reach and the potential for personalization, social media will play an increasingly important role in global advertising strategy as they penetrate not only the daily lives of consumers but also business practices (Okazaki and Taylor, 2013).

Facebook enables a business to select its audience by location, age, and interest. A business can advertise its website, its products, or an event (Debobo, 2012). The cost for a Facebook ad campaign is much lower than that of traditional ads and there is additional control, as a daily budget can be set which can change at any time. The 
advertiser is billed whenever a pay per click or an impression is performed. Facebook offers Business Manager, which is a business account management system. It enables the creation, editing, conversion, audience creation and reporting of its advertising campaigns. In addition, there is the feature of Facebook Pixel, which is a code snippet that is placed on the business website and allows tracking and targeting visitors to the business website. Facebook ads can be as simple or complex as the advertiser wants. It offers easy creation and promotion of advertising campaigns. Facebook is a great option for reaching out to existing and future customers.

\subsection{Facebook}

Users spend a lot of time on Facebook every day, interacting with pages, groups, events and publishing their own content. Facebook enables charities to publish information about their action, share events, news, photos and related videos (Voigt, 2010). In Facebook's world, a small charity has the potential to reach just as many potential donors as a large charity.

Facebook donors usually make small donations and are more prone to certain categories of charity, especially those related to health and which reflect immediate needs or benefits for the general public. According to a study by Saxton and Wang (2014), there is a strong relationship between the size of the charity's social network and the receipt of charitable donations. Supporters of the charity appear to be donating money through social networks, also attracting their online friends, which in the end significantly increases charitable donations. The emotional pressure that comes from one's social network and the desire of observers to contribute to that network seems to be a large part of the donation decision on Facebook. Charities interested in raising money from social media develop strategies that increase the number of online donations and encourage their supporters to take action by promoting the organization and its purpose while attracting even more supporters.

The prevalence of smartphones, tablets and netbooks means that potential audiences can be reached anywhere (Satchell and Foth, 2012). More than 2.37 billion people use Facebook and 330 million Twitter, while YouTube has 20 billion of users (Clement, 2019). Organizations focus on creating and maintaining strong relationships with their audiences. Social media has fundamentally transformed the world of nonprofits, providing a valuable way to engage with a larger audience and promote their cause more effectively (Kanter, 2012).

Facebook's audience growth can be achieved by inviting people to "like" the page. If the Facebook page is attractive and manages to make the mission of the organization accessible to everyone, then Facebook users will spend more time exploring it. Vivid images, in combination with refreshed and rich content, lead to this goal. When the organization's posts appear on Facebook's News Feed they can be reached by existing and future supporters. Facebook users see and interact primarily with the posts that appear on the Facebook News Feed, where they spend most of their time. If 100 people 
press like button on an organization's page, only 10 of them will see a post posted by the organization on Facebook's News Feed (Younan, 2017).

One way to boost an organization's appeal is paid advertising via Facebook. It is not necessary to invest large amount of money for such advertising campaigns. A maximum budget may be set to control expenditure. So, even if the budget is extremely small, there are many advertising options available through the Facebook platform. The organic and paid approach are not treated as two separate marketing initiatives. For example, if a major upcoming event or campaign has been targeted for a specific purpose, then even if it has many likes and notifications, it can perform much better if a small amount is invested. This kind of promotion can target specific people who might be interested in the campaign or the event with specific demographic criteria.

Initially, a pay-per-click (PPC) advertising campaign can be created. In addition, users outside of the organization's network can be reached by their current friends and followers. Paid ads appear with the Sponsored tag in the news feed. It's a good option to boost the charity's marketing efforts. Advertising can last as long as the organization wants and there are different approach and targeting options, based on demographics such as location, age, gender, etc.

\section{Methodology}

The goal of this research was to identify the appropriate targeting method that an organization should follow in order to increase the effectiveness of social media advertising. In particular, the aim was to outline the profile of donors and the variables that contribute to a successful online charity advertising campaign. In order to investigate the online promotion strategy of a charity, the implementation of such an internet plan is presented.

The research was carried out in a non-profit Greek charity in Thessaloniki, which operates in the health sector and has presence in various cities of Greece. Two groups of advertising campaigns were created that focused on the following two cases. The first one was about a Christmas Lottery, that the organization held during Christmas period. Every user could visit the organization's website and assist the charity with the purchase of lotteries, with the main prize to be a car. The second group of advertising campaigns was based on a promotional video exhibiting the charity's actions and its aim was to collect donations through the charity's website. Through the video campaign, the user was taken to the organization's website and he could optionally offer a donation through the donation button on the site.

\section{Research Results}

During the investigation, several experiments were carried out in order to find the best performing campaign. A total of eight campaigns were created that targeted to 
different areas, audience, placement, interests, and behaviours. The campaigns carried out from 21/12/18 until 08/01/19 (19 days) with the aim to be the collection of donations. Conversions were measured and results retrieved via Facebook Business Manager.

Below, all the campaigns that were created are presented in detail. The target that each of them had and the conclusions that were drown are presented. Afterwards, a comparison between them is performed. The metric on which the comparison between the campaigns is based, is that of the "Return On Advertising Spend" (ROAS). It is calculated based on the following formula:

ROAS $=\frac{\text { (Gross Revenue from Advertisement campaign })}{(\text { Cost of Advertisement Campaign })}$

Of course, ROAS should be at least greater than 1 in order the revenue to overcome costs, but the value of a decent ROAS depends on operating expenses, profit margins and the overall health of the business. Although there is no a "correct" answer to what a good ROAS is, a value of 4 is consider as a good value by various (Bigcommerce, 2019).

Campaign \#1: Lottery_Big_Cities:

This campaign targeted men and women who live in Athens and Thessaloniki (the two main big Greek cities), at the ages between 24-65+. It was the campaign with the biggest success having a total of 207 purchases. The purchases are equally divided between men and women and ages between 35 to 44 made the most of them (56\%). The ROAS of this particular campaign was 7.93 which means that the earned amount was 7.93 times the initial investment amount. It contributed $56.7 \%$ of the income of all the performed campaigns.

Campaign \#2: Lottery_fblike_friends:

This campaign targeted people who pressed "like" to the charity's Facebook page, they live in Greece and they are men or women at the ages between 18-65+. A total of 30 purchases were made and most of them were made by women (63\%). Among the female population, most purchases were made from women between the ages of 25-54. Regarding the male population, most purchases were made from men between the ages 35-54. The ROAS of this campaign was 5.6 which means that the earned amount was 5.6 times the initial investment amount. In comparison with the total performance of all campaigns, it contributed the $11.9 \%$ of the total income.

Campaign \#3: Lottery_friends of fblike friends:

This campaign targeted people who are friends of people who presses "like" to the charity's Facebook page, they live in Greece and they are men or women at the ages between 18-65+. The ROAS of this campaign was 6.88 which means that the earned amount was 6.88 times the initial investment amount. It contributed the $21.1 \%$ of the total income. It seems that when users see friends on their social network, to like or 
associate with a Facebook page, this is one factor that would motivate them to do the same (Smith, Windmeijer and Wright, 2012). This conjecture seems to be present on our present research as this campaign was the second-best campaign in the experiment. A total of 106 purchases were made with most of the purchases to be made by women (59\%), compared to $41 \%$ that were made by men. Most purchases were made by women of age 25-34.

Campaign \#4: Lottery_charitable_interests:

This campaign targeted people who are interested in charitable and humanitarian activities, they live in Greece and they are men or women at the ages between 18-65+. A total of 25 purchases were made. Most purchases were made by women of age 35 44. Surprisingly, this campaign did not deliver as expected, although according to Reinstein (2011) when a person donates to one type of charity, there is an increased likelihood of donating to other types of charity as well. This campaign was interrupted relatively quickly due to its low performance. The ROAS of this campaign was 1.85 . It contributed the $2.6 \%$ of the total income.

Campaign \#5: Lottery_charity's_2018_events:

This campaign targeted people who showed interest in participating in events organized by the Greek charity organization in 2018. All purchases (7) were made by women aged 45-54. The ROAS of this campaign was 1.43 . It contributed the $0.7 \%$ of the total income. This campaign did not perform as expected and it was a negative surprise.

Campaign \#6: Lottery_lookalike_fblike_charitable_friends:

This campaign targeted to an audience that had 1\% similar features to the existing audience of people who had pressed "Like" on the charity's Facebook page. All purchases (5) were made by women aged from 35-44. The ROAS of this campaign was 0.89 . It contributed the $0.3 \%$ of the total income. This campaign did not perform as expected and it was a negative surprise too.

\section{Campaign \#7: Charity's video:}

This campaign targeted people who live in the two main big Greek cities (Athens and Thessaloniki), men and women at the ages between 23-65. Most purchases were made by women between 35-44. A total of 5 purchases were made. The ROAS of this campaign was 2.14 . It contributed the $3.1 \%$ of the total income. Although the video clip that the campaign was presenting was of high quality and it was watched a lot, it didn't deliver as expected.

Campaign \#8: Charity's video fblike friends:

This campaign targeted people who had pressed "Like" on the charity's Facebook page, they live in Greece and they are men or women, at the ages between 18-65+. A total of 4 purchases were made. All purchases were made by men at the ages between 25-44. The ROAS of this campaign was 3.12. It contributed the $3.6 \%$ of the total 
income. The same targeting worked better for the lottery campaign, though in that particular campaign, it did not deliver as expected.

Table 1 below shows all the performed campaigns. Based on ROAS, the best performed campaign was campaign \#1: Lottery_Big_Cities. 57\% of the total income came from this campaign and it had the highest ROAS (7.93) from all campaigns. Second best performed campaign was the lottery campaign targeted people who are friends of people who like the charity page (campaign \#3: lottery_friends of fblike friends) that had the $21 \%$ of total income and a ROAS of 6.88 . Figure 1 exhibits these results.

Table 1. All Facebook advertising campaigns

\begin{tabular}{|l|l|l|l|l|l|}
\hline $\begin{array}{l}\# \\
\text { No }\end{array}$ & Campaign name & $\begin{array}{l}\text { Expenses } \\
(\%)\end{array}$ & $\begin{array}{l}\text { Income } \\
(\%)\end{array}$ & $\begin{array}{l}\text { Return On } \\
\text { Advertising } \\
\text { Spend } \\
\text { (ROAS) }\end{array}$ & $\begin{array}{l}\text { Purchase } \\
\text { s }\end{array}$ \\
\hline 1 & lottery_Big_Cities & 41.4 & 56.7 & 7.93 & 207 \\
\hline 2 & lottery_fblike friends fblike & 12.3 & 11.9 & 5.6 & 30 \\
\hline 3 & $\begin{array}{l}\text { lottery_friends of } \\
\text { friends }\end{array}$ & 17.7 & 21.1 & 6.88 & 106 \\
\hline 4 & lottery_charitable_interests & 8 & 2.6 & 1.85 & 25 \\
\hline 5 & $\begin{array}{l}\text { lottery_charity's_2018_event } \\
\text { s }\end{array}$ & 3 & 0.7 & 1.43 & 7 \\
\hline 6 & $\begin{array}{l}\text { lottery_lookalike_fblike_ } \\
\text { charity's friends }\end{array}$ & 2.6 & 0.3 & 0.89 & 5 \\
\hline 7 & charity's video & 8.4 & 3.1 & 2.14 & 5 \\
\hline 8 & charity's video_fblike friends & 6.6 & 3.6 & 3.12 & 4 \\
\hline & Total & $100 \%$ & $100 \%$ & & 389 \\
\hline
\end{tabular}

Figure 1. All Facebook advertising campaigns

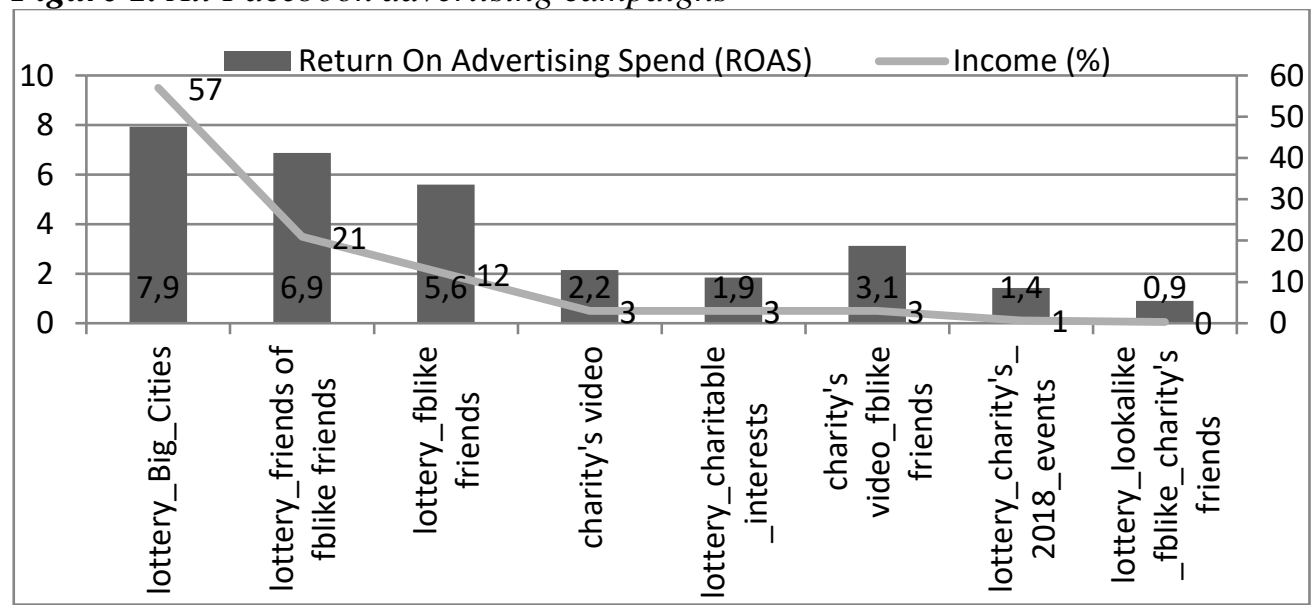


The analysis of purchases by gender is shown in Figure 2. It is interesting to mention that although the number of purchases made by women is higher, the largest amount was donated by men. Most purchases were made by people at the ages between 35-44 years $(46 \%$ ) (see Figure 3), with 179 purchases in total and a high ROAS (7.6). The largest amount was collected from these ages. This may be justified by the fact that they have enough income and at the same time, they are using internet more than older ages. There were few purchases over the age of 55. This may be due to the lack of trust in technology/internet and the fear of donating online. People at the ages between 18-24 made few purchases too. This may be due to the lack of income. Men and women aged 35-44 donated the most money, followed by men aged 45-54.

Figure 2. Purchases and income by gender

\begin{tabular}{r|c|c|}
\multirow{2}{*}{$100 \%$} & \multicolumn{3}{|c|}{} \\
\cline { 2 - 3 } $0 \%$ & \multicolumn{3}{|c|}{} & \\
\cline { 2 - 3 } & Purchases $\%$ & Income $\%$ \\
\hline male & $43 \%$ & $52,3 \%$ \\
\hline female & $57 \%$ & $47,7 \%$ \\
\hline
\end{tabular}

Figure 3. Purchases by age

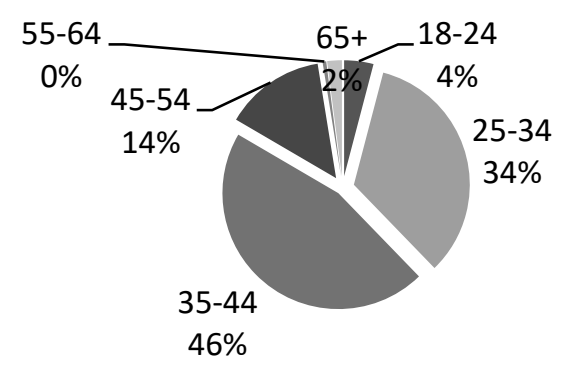

The time of the day when most purchases were made was at $8 \mathrm{pm}$ (35 purchases, see figure 4). A lot of purchases were also made at 12pm (31 purchases) and 1pm (29 purchases), $5 \mathrm{pm}$ (28 purchases) and $7 \mathrm{pm}$ (28 purchases).

Figure 4. Purchases timeframe

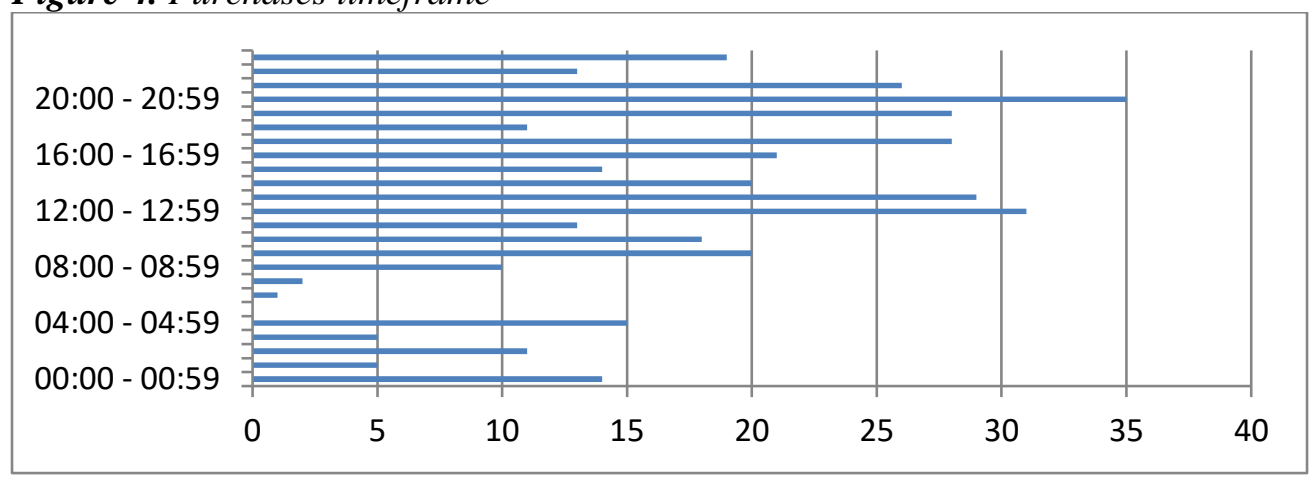


The most profitable donations seem to be (Figure 5) those made on 27.12, 4.01, 5.01 and 7.01, since in those days, while we had reduced expenses spending per day, the campaigns were going viral and constantly showing up, doing better. This happens because during this period, people are more positive, and they have both time and mood to support good actions. The largest amounts were donated on 25.12, 01.01.19 and 02.01.19. Very large amounts were also donated on 23.12, 24.12 and 07.01. Furthermore, most of the purchases were made by android devices (77\%), while $15 \%$ made purchases via PC and $8 \%$ through iOS (see figure 6).

Figure 5. Purchases by date

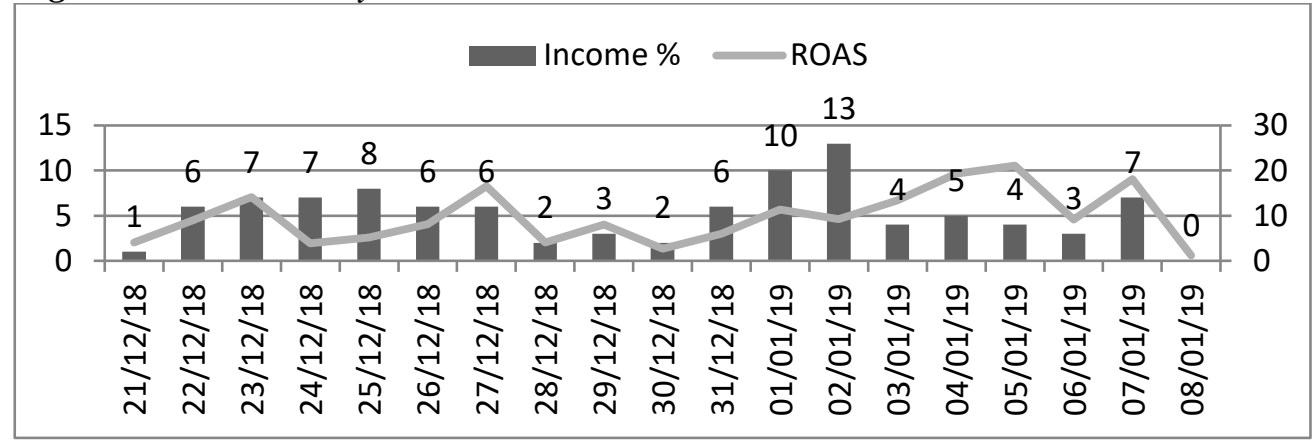

Figure 6. Purchases by device

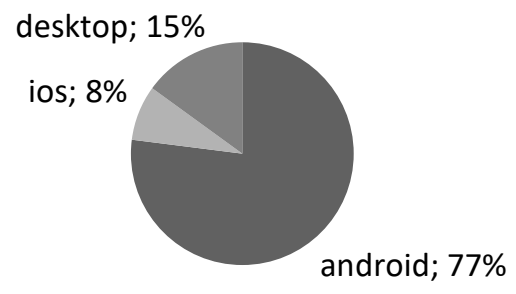

\section{Conclusions, Recommendations and Future Research}

Analyzing the outcomes of the performed campaigns, the following conclusions were drawn:

- Most purchases were made by people at the ages between 35-44.

- Although most purchases were made by women, men appeared to donate more money.

- Most purchases were made on 25.12, 31.12 and 02.01, while the largest amount was donated on 01.01.19 and 02.01.19, with afternoon hours generally performing better. This is in line with Blackbaud's (2018) annual report that states that the month of the year that most donations are made is December. On festive days people are more positive about helping a social cause, have more time to navigate and have a better financial situation. 
- The best performing campaigns were those of the lottery aimed to big cities (Athens and Thessaloniki), as well as the lottery campaign dealing with people who are friends of people who like the charity's page.

- The campaigns that did not performed so well as expected are a) the campaign that targeted people who show interest in charity and humanitarian actions, b) the campaign that targeted people who showed interest in charity's events in 2018, and c) the campaign that targeted at people that have similar features with people who had liked the charity's Facebook page.

- In general, the lottery was preferred by the public over video campaign. Although the video of the video campaign was very good and it was watched a lot, it didn't deliver as expected. This may have happened because the donation message was not obvious. The lottery campaigns on the other hand, had a positive effect on people since there was a car prize. The expectation to win a Christmas present pushes people to try their luck.

The above conclusions can be used to help charities to choose the right targeting and digital strategy in order to a) attract new supporters / donors, b) strengthen the charity's relationship with existing ones, and c) lead to increased donations. This is because one of the challenges facing organizations is to develop a digital strategy that will make users pay attention and eventually interact with the organization (Voigt, 2010).

Charities need to adopt a digital strategy and identify how, when and where people donate. Attractive images, refreshed content, continuous and daily interaction with people, posts about the work of the organization, photos of staff and volunteers, events, a high-quality website, email communication, are just some of the actions that charities should take if they want to create greater engagement, volunteering and support. Proper audience-targeted advertising campaigns, highly-targeted postings, and an engaging Facebook page are integral tools for their action.

According to Axelrad (2018), people who come into contact with the organization through multiple "channels" donate more and remain loyal for longer. If this is quantified, then one could say that they make at least $20 \%$ more money than those who come into contact with the organization through a single 'channel'. If organizations want to attract more donations, using multi-channel marketing is a necessity. The results of this research can provide a solid starting point for future research on how charities can use the Internet to their advantage and establish a successful digital strategy. The research can be extended to various annual periods, countries and charity topics and the results can be combined, compared and evaluated.

The findings will help charities use the right targeting method to attract new supporters / donors, strengthen the charity's relationship with existing ones and lead to increased donations. 


\section{References:}

Angelou, L.M. 2018. How technology is changing the way we look at nonprofits. [online] Available at: <https://code.likeagirl.io/how-technology-is-changing-the-way-welook-at-nonprofits-738010af51fe $>$ [Accessed 20 October 2018].

Axelrad, C. 2018. The 9 Signs of a Successful Social Media Strategy for Nonprofits. [online] Available at: <https://maximizesocialbusiness.com/social-media-strategy-fornonprofits-25696/> [Accessed 25 October 2018].

Bendapudi, N., Singh, S. and Bendapudi, V. 1996. Enhancing Helping Behavior: An Integrative Framework for Promotion Planning. Journal of Marketing, [e-journal] 60(3), 33-49. Available at:

<https://www.jstor.org/stable/1251840?seq=2\#metadata_info_tab_contents> [Accessed 15 November 2018].

Big commerce. 2019. What is ROAS? Calculating Return On Ad Spend. [online] Available at: <https://www.bigcommerce.com/ecommerce-answers/what-is-roas-calculatingreturn-on-ad-spend/> [Accessed 8 October 2019].

Blackbaud. 2018. The status of UK Fundraising 2018 Benchmark Report. [online] Available at: <https://hub.blackbaud.co.uk/npinsights/the-status-of-uk-fundraising-2018benchmark-report $>$ [Accessed 15 January 2019].

Chen, W. and Givens, T. 2013. Mobile donation in America. Mobile Media \& Communication, 1(2), 196-212.

Clement, J. 2019. Most famous social network sites 2019, by active users. [online] Available at: <https://www.statista.com/statistics/272014/global-social-networks-ranked-bynumber-of-users/> [Accessed 10 October 2019].

Debobo, G. 2012. 5 of the Biggest and Still the Best Online Advertising Methods. [online] Available at: <https://www.business2community.com/online-marketing/5-of-thebiggest-and-still-the-best-online-advertising-methods-0186358> [Accessed 6 January 2019].

Foux, G. 2006. Consumer-generated media: Get your customers involved. Brand Strategy, 202, 38-39.

Ncvo. 2018. Fundraising. [online] Available at: <https://knowhow.ncvo.org.uk/funding/fundraising> [Accessed 15 September 2018].

Goldfarb, A. 2014. What is Different About Online Advertising? Review of Industrial Organization, [e-journal] 44(2), 115-129. Available at: https://link.springer.com/content/pdf/10.1007\%2Fs11151-013-9399-3.pdf> [Accessed 2 February 2019].

Kanter, B, Paine, K.D. and Paarlberg, W.T. 2012. Measuring the Networked Nonprofit: Using Data to Change the World. San Francisco: Jossey-Bass.

Kaplan, A.M. and Haenlein, M. 2010. Users of the World, Unite! The Challenges and Opportunities of Social Media, Business Horizons, [e-journal] 53(1), 59-68. Available at: <http://michaelhaenlein.eu/Publications/Kaplan,\%20Andreas\%20\%20Users\%20of\% 20the\%20world,\%20unite.pdf> [Accessed 13 January 2018].

Kollowe, J. 2017. Google and Facebook bring in one-fifth of global ad revenue. [online] Available at: <https://www.theguardian.com/media/2017/may/02/google-andfacebook-bring-in-one-fifth-of-global-ad-revenue> [Accessed 29 January 2019].

Ogden, T. and Laura, S. 2009. Social Networking and Mid-Size Non-Profits: What's the Use. [pdf] Available at: 
<http://philanthropyaction.com/documents/Social_Networks_and_Mid-Size_NonProfits.pdf> [Accessed 6 October 2018].

Okazaki, S. and Taylor, C.R. 2013. Social media and international advertising: theoretical challenges and future directions. International Marketing Review, [e-journal] 30(1), 56-71. http://dx.doi.org/10.1108/02651331311298573.

Reinstein, D. 2011. Does one charitable contribution come at the expense of another? [online] Available at: <http://www.bepress.com/bejeap/vol11/iss1/art40> [Accessed 12 November 2018].

Satchell, C. and Foth, M. 2012. The Re-creation of Identity in Digital Environments and the Potential Benefits for Non-Profit and Community Organization's. Journal of Community, Citizen's \& Third-Sector Media \& Communication, [e-journal] 4, 1627. Available at: <https://eprints.qut.edu.au/14648/1/satchel.pdf> [Accessed 12 November 2018].

Saxton, G.D. and Wang L. 2014. The Social Network Effect: The Determinants of Giving Through Social Media. Nonprofit and Voluntary Sector Quarterly, [e-journal] 43(5), 850-868. Available at:

<https://papers.ssrn.com/sol3/papers.cfm?abstract_id=2247138> [Accessed 12 December 2018].

Schervish, P.G. and Havens, J.H. 1997. Social participation and charitable giving: a multivariate analysis, [e-journal] 8, 235-260. Available at:

<https://link.springer.com/content/pdf/10.1007\%2FBF02354199.pdf> [Accessed 31 October 2018].

Shier, L.M. and Handy, F. 2012. Understanding online donor behavior the role of donor characteristics, perceptions of the internet, website and program, and influence from social networks. International Journal of Nonprofit and Voluntary Sector, [e-journal] 17(3), 219-230. Available at:

<https://onlinelibrary.wiley.com/doi/full/10.1002/nvsm.1425> [Accessed 1 February 2019].

Smith, B.G. 2012. Socially distributing public relations: Twitter, Haiti, and interactivity in social media. Public Relations Review, [e-journal] 36(4), 329-335. Available at: <https://www.sciencedirect.com/science/article/pii/S0363811110000809> [Accessed 1 October 2018].

Smith, S., Windmeijerand, F. and Wright, E. 2012. The effect of social information on charitable donations: Evidence from the (running) field. [pdf] Available at: <https://www.parisschoolofeconomics.eu/IMG/pdf/may2012-paris-smithwindmeijer-wright.pdf $>$ [Accessed 1 December 2018].

Steele, V. and Elder, S.D. 1992. Becoming a fundraiser: The principles and practice of library development. Chicago: American Library Association.

Strawmyer, L. 2014. Social Media in the Social Sector. Thesis. Indiana University Bloomington. Available at: $<$ https://spea.indiana.edu/doc/undergraduate/ugrd_thesis2014_pnmgmt_strawmyer.p df $>$ [Accessed 2 February 2019].

Voigt, L. 2010. A Non-Profit Guide to Social Media How to build a presence in the social networking world. Syracuse University Honors Program Capstone Projects, [ejournal] 371. Available at: <https://surface.syr.edu/honors_capstone/371> [Accessed 1 September 2018].

Wang, L. and Graddy, E. 2008. Social capital, volunteering, and charitable giving. International Journal of Voluntary and Nonprofit Organizations, [e-journal] 19, 23- 
42. Available at: 〈https://link.springer.com/article/10.1007/s11266-008-9055-y> [Accessed 9 February 2019].

Younan, C. 2017. Driving results with Facebook (Part One). [online] Available at: $<$ https://charityinfo.ca/articles/FacebookResults?platform=hootsuite> [Accessed 5 December 2018].

Zotos, G.X. 2008. Advertising. 5th ed. Thessaloniki: University Studio Press. 